\title{
Dexamethasone reduced the incidence of children with mild croup who returned for medical care
}

Bjornson CL, Klassen TP, Williamson J, et al; for the Pediatric Emergency Research Canada Network. A randomized trial of a single dose of oral dexamethasone for mild croup. N Engl J Med 2004;351:1306-13.

Does dexamethasone reduce the incidence of children with mild croup who return for medical care more than placebo?

METHODS

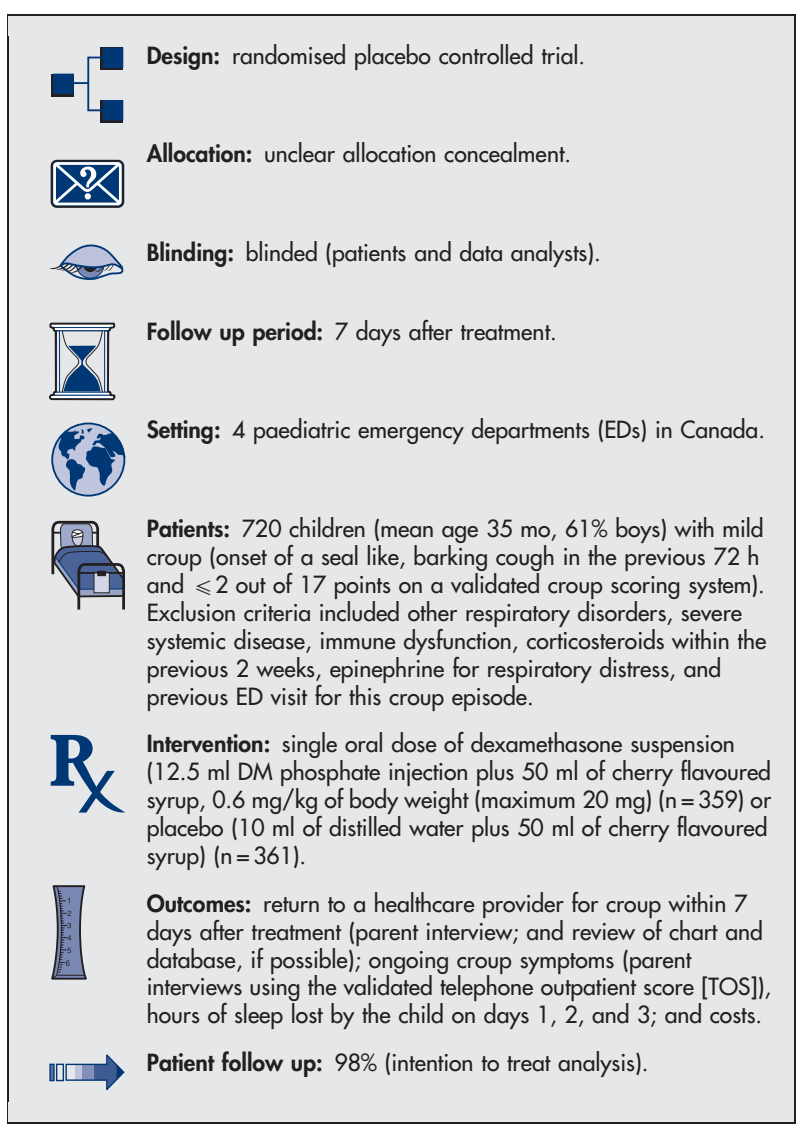

\section{MAIN RESULTS}

Fewer children who received dexamethasone returned for medical care than did those who received placebo (table). On day l, a smaller

For correspondence: Dr D W J Johnson, Child Health Research Group Alberta's Children's Hospital, Calgary, Alberta, Canada. david.johnson@ calgaryhealthregion.ca

Sources of funding: Canadian Institutes of Health Research; Alberta Children's Hospital Foundation; Children's Hospital of Eastern Ontario Research Institute; Stollery Children's Hospital Foundation.

Dexamethasone (DM) $v$ placebo for mild croup in children*

\begin{tabular}{lllll}
\hline Outcome at 7 days & DM & Placebo & RRR $(95 \%$ Cl) & NNT (CI) \\
\hline Return to medical care & $7.3 \%$ & $15 \%$ & $52 \%(25$ to 69$)$ & 13 (8 to 31$)$
\end{tabular}

*Abbreviations defined in glossary; RRR, NNT, and Cl calculated from data in article. proportion of children in the dexamethasone group had severe croup (ie, higher TOS) (adjusted odds ratio 3.4, 95\% CI 1.6 to 7.4 ), but by day 3, the groups did not differ, and symptoms had resolved in $>75 \%$ of children. Children who received dexamethasone lost less sleep than those who received placebo $(2.9 v 4.2 \mathrm{~h}, \mathrm{p}<0.001)$. The cost of dexamethasone was lower than placebo for the payer (provincial government; CN\$18 v \$25, p<0.001), non-payer (family; CN\$54v $\$ 68, \mathrm{p}<0.001)$, and society ( $\mathrm{CN} \$ 72 v \$ 93$ per case of croup; average savings/case CN $\$ 21, \mathrm{p}=0.01$ ).

\section{CONCLUSIONS}

Dexamethasone reduced the incidence of returning to medical care and sleep loss in children with mild croup. Fewer children in the dexamethasone group than the placebo group reported more severe symptoms on day 1 , but this difference disappeared by day 3 . Patients in the dexamethasone group had lower payer, family, and societal costs than those in the placebo group.

Commentary

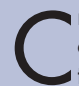

roup is a common cause of upper respiratory obstruction in children, and although it is self limiting, it places a large burden on the healthcare system. ${ }^{1}$ Since the late 1980s, clear benefit of intramuscular dexamethasone for children admitted to hospital with croup has been established. ${ }^{2}$ The study by Bjornson et al adds to the current body of research on oral dexamethasone for children with mild croup, who are treated on an outpatient basis. ${ }^{3}$ This study has many strengths including use of a multicentre randomised trial design; a reliable and valid croup symptom scale; a wide range of outcomes (including social factors and a cost analysis); monitoring for adverse events; an appropriate sample size to achieve $80 \%$ power; intention to treat analysis; and almost complete follow up. Data about whether the parent informants were the primary caregivers would have provided readers with information about possible informant effects on such outcomes as the number of hours of lost sleep and stress on the parent as the main caregiver.

The major study finding of reduced return visits for medical care, while modest in effect, is important from both parental and healthcare perspectives. In addition, reduced return visits likely led to decreased stress for children with croup. The findings are consistent with a recent systematic review by the Cochrane Acute Respiratory Infections Group. ${ }^{3}$ Given the improved patient and parental outcomes, low complication rate, reduced costs, and consistency of the findings with a recent systematic review, the findings support a change in practice. Nurses and nurse practitioners should work collaboratively with physicians to develop best practice primary care guidelines for children with mild croup and teach parents about the importance of dexamethasone as a single dose treatment for mild croup.

Linda O'Mara, RN, PhD School of Nursing, McMaster University Hamilton, Ontario, Canada

1 Feldman ME. Croup. In: Feldman W. Evidence-based pediatrics. Hamilton [Ontario]; St Louis: BC Decker, 2000:177-90.

2 Kairys SW, Olmstead EM, O'Connor GT. Steroid treatment of laryngotracheitis: a meta-analysis of the evidence from randomized trials. Pediatrics 1989:83:683-93.

3 Russell K, Wiebe N, Saenz A, et al. Glucocorticoids for croup. Cochrane Database Syst Rev 2004;(1):CD001955. 